\title{
Knowledge and awareness of cervical cancer and its prevention among nursing staff of a tertiary care teaching institute in South India
}

\author{
Sneha Badwe Dhodapkar ${ }^{1}$, Ramesh Chand Chauhan ${ }^{2} *$, Shilpa Thampy ${ }^{3}$
}

\author{
${ }^{1}$ Department of Obstetrics \& Gynecology, Pondicherry Institute of Medical Sciences, Puducherry-605014, India \\ ${ }^{2}$ Department of Community Medicine, Pondicherry Institute of Medical sciences, Puducherry-605014, India \\ ${ }^{3}$ Undergraduate Student, Pondicherry Institute of Medical Sciences, Puducherry-605014, India
}

Received: 20 October 2014

Accepted: 1 November 2014

\section{*Correspondence:}

Dr. Ramesh Chand Chauhan,

E-mail: rcchauhan21@gmail.com

Copyright: (c) the author(s), publisher and licensee Medip Academy. This is an open-access article distributed under the terms of the Creative Commons Attribution Non-Commercial License, which permits unrestricted non-commercial use, distribution, and reproduction in any medium, provided the original work is properly cited.

\begin{abstract}
Background: Cervical cancer is the second leading cause of morbidity and mortality among the females worldwide. India has the highest burden of cervical cancer patients, accounting for approximately one-fifth of the cases in world. Nurses being an important link between the doctors and female patients in OPD or wards, it is imperative that they should be aware of the facts about cervical cancer and especially of screening techniques which can be utilized in low-resource settings.

Methods: A cross-sectional interview based study was done among 200 nurses of a tertiary care teaching institute from June 2013 to July 2013, to assess the knowledge and awareness of nursing staff regarding causes of cervical cancer and its prevention and early detection.

Results: Among all participated nurses, $85 \%(\mathrm{n}=170)$ were aware of the term cancer cervix and $45 \%$ reported that it is the most frequent gynaecological cancer in India. Only $30.6 \%$ reported that it is the leading cause of death among women due to cancer. Young age at first intercourse, multiple sex partners, cigarette smoking, high parity and lower socio-economic status were correctly responded by $13 \%, 48 \%, 16 \%, 9 \%$ and $13 \%$ of participants respectively, as risk factors for cervical cancer. None of the participants knew about the VIA method of screening for cervical cancer. Among 119 of those participants who knew that cervical cancer can be detected by Pap smear, only $5(4 \%)$ had ever undergone Pap smear examination.

Conclusions: Nurses identify certain aspects of cervical cancer correctly but their knowledge is not adequate, hence necessary changes should be made in their curriculum.
\end{abstract}

Keywords: Cervical cancer, Nurses, Knowledge, Screening

\section{INTRODUCTION}

Globally, with an estimated 529000 new cases and 275000 deaths in 2008 , cervical cancer is the second most common cancer in women. ${ }^{1}$ More than $85 \%$ of the new cases and about $88 \%$ of deaths due to cervical cancer occurs in developing countries. ${ }^{1}$ It is the commonest malignancy among women in India. ${ }^{2}$ With the estimated 132000 new cases and 74000 deaths every year, India accounts for one-fifth of the case in world. ${ }^{3}$ Among all major female genital malignancies, cancer cervix is largely preventable because it has pre-invasive and a micro-invasive stages that can be detected early by screening and then effectively treated. However, competing health care priorities, insufficient financial resources, weak health systems, and limited numbers of trained providers have made high coverage for cervical cancer screening in most low- and middle-income countries difficult to achieve. ${ }^{4}$

The annual incidence and mortality from cancer cervix has gone down by $50-70 \%$ in many developed countries because of the introduction of population based screening. ${ }^{5}$ At least once in a life time, a minimum screening is recommended for every woman $30-49$ years 
of age. ${ }^{4}$ But, in India, there is no organised screening programmes for cervical cancer. ${ }^{6}$

With the existing screening scenario the onus lies on the women themselves to get screened. In the absence of organised screening programmes, opportunistic screening is an alternative where a female presenting to the hospital should be screened for cervical cancer.

Nurses being an important link between the doctors and female patients in OPD or wards, it is imperative that they should be aware of the facts about cervical cancer and especially of screening techniques which can be utilized in low-resource settings. Also, some studies have shown that recommendation of cervical cancer screening to females by medical professionals, including nurses, improves screening coverage among the general population. ${ }^{7-9}$ Because nurses play an integral role in educating women in prevention of diseases and health promotion, they influence cervical cancer screening adherence and health activities among most women. ${ }^{8,10}$ Therefore, knowledge among nurses, regarding cervical cancer and its prevention is quite important and nurses should have current and accurate knowledge about HPV to promote informed decisions about cervical cancer screening. This study was done to assess the knowledge among nursing staff about cervical cancer and its prevention and to explore the attitude and practices among nurses in terms of cervical cancer screening such as pap smear with a view to sensitize them as a first step towards increasing screening uptake in the community. Also, there are few studies on actual cervical cancer screening adherence of nurses. The observations from this study will be useful to complement the knowledge and awareness about this important public health issue.

\section{METHODS}

A cross- sectional interview based study was done among 200 nurses of tertiary care teaching institute, from June 2013 to July 2013. The study protocol was approved by Institute Ethics Committee (IEC) of Pondicherry Institute of Medical Sciences. Each participant received written explanations about the objectives of the study. Written informed consent for all the participants was obtained before starting the interview.

A pre-tested structured questionnaire was used to interview the participants. The questionnaire was divided into two main parts; first dealing with the sociodemographic information about the participants and second consisting of the questions regarding the knowledge and awareness about different aspects of cervical cancer and its screening. The original questionnaire was in English and was also translate in local language (Tamil).

The collected data was entered on the excel spreadsheet version 2010, processed and analysed by SPSS 16.0 version. Proportions and means were calculated for categorical and continuous variables respectively. Chi square test was applied to find the association among different variables. $P$ value of $<0.05$ was considered significant.

\section{RESULTS}

All the study participants were female. Majority of the participants $159(79.5 \%)$ were in the age group of 20-24 years (Range 20-47 years). Amongst the participants interviewed, 148 (74\%) had completed BSc Nursing degree and 52 (26\%) were diploma holder in general nursing.

Among 200 study participants, only $170 \quad(85 \%)$ participants were correctly aware of the cancer cervix. Further knowledge regarding cervical cancer prevention was assesses among 170 nurses. Of them, 77 (45\%) responded that cancer cervix is the most common gynaecological cancer in India and $31 \%$ responded that it is the leading cause of mortality amongst the gynaecological cancer. Regarding the knowledge of risk factors, $48 \%$ and $9 \%$ participants reported multiple sexual partners and high parity as risk factor for cancer cervix respectively. Majority (87\%) didn't knew that young age at first intercourse is a risk factor and only $15.9 \%$ and $12.9 \%$ of respondent were aware that cigarette smoking and low socio economic status are associated with cancer cervix.

Table 1: Knowledge about causes of cervical cancer and its risk factors.

\begin{tabular}{|c|c|c|}
\hline \multirow[t]{2}{*}{ Variable } & \multicolumn{2}{|c|}{$\begin{array}{l}\text { Correct } \\
\text { response }\end{array}$} \\
\hline & $\mathbf{n}$ & $\%$ \\
\hline Are aware of cervical cancer & 170 & 85.0 \\
\hline \multicolumn{3}{|l|}{ Risk factors } \\
\hline Young age at first intercourse & 22 & 12.9 \\
\hline Multiple sex partners & 82 & 48.2 \\
\hline Smoking & 27 & 15.9 \\
\hline High parity & 16 & 9.4 \\
\hline Lower socio-economic status & 22 & 12.9 \\
\hline Family history of cervical cancer & 55 & 32.4 \\
\hline Contraception use & 16 & 9.4 \\
\hline \multicolumn{3}{|l|}{ Cause of cancer } \\
\hline Genetic & 57 & 33.5 \\
\hline Infection & 80 & 47.1 \\
\hline Environmental & 4 & 2.4 \\
\hline Virus infection can lead to cervical cancer & 49 & 28.8 \\
\hline $\begin{array}{l}\text { Virus infection responsible for cervical } \\
\text { cancer is HPV }\end{array}$ & 38 & 22.3 \\
\hline
\end{tabular}

*HPV - Human Papilloma Virus

Most of the participants (47\%) responded that cancer cervix is caused by infection, but $33.5 \%$ reported it to be a genetic disorder, and another $2.4 \%$ associated it with environmental factors. Among those who responded infection as causative factor $(n=80)$, majority $61.3 \%$ 
knew it is caused by viruses and only $47 \%$ correctly identified Human Papilloma Virus (HPV) as the causative virus. Another $14 \%$ and $7.5 \%$ reported bacteria and fungus to be responsible for causing cervical cancer (Table 1).

Regarding the symptoms of cancer cervix, excessive vaginal bleeding, malodorous vaginal discharge and abdominal pain was reported by $14.7 \%, 42.4 \%$ and $34 \%$ of participants. Only $22.9 \%$ of participants knew that cancer cervix can lead to post coital bleeding.

Regarding the diagnosis and screening of cervical cancer, $80.6 \%$ of participants knew that there are test available for early detection of cancer cervix and $70 \%$ reported that Pap smear can be used for the same. Only 2 (1.4\%) knew that HPV DNA testing can be used for early detection. None of them knew that pre-cancerous lesion of cervix can be detected by Visual Inspection of Cervix after application of acetic acid (VIA).

Of the 119 participants who knew that Pap smear is used for early detection of cancer cervix, 112 (94.1\%) participants correctly knew that it is cervical smear. Also, $40.3 \%$ of these correctly reported that Pap smear screening should be started at 21 years of age and $50.4 \%$ responded that Pap smear should be done every year. Only 5 (4\%) participants had undergone Pap smear examination for themselves (Table 2). The reasons for not having it done were mainly not having any symptoms $64(56 \%)$, not having any risk factors $36(31.5 \%)$.

Table 2: Knowledge about symptoms of cervical cancer and its prevention among Nurses $(n=170)$.

\begin{tabular}{|c|c|c|}
\hline Variables & n & $\%$ \\
\hline \multicolumn{3}{|l|}{ Symptoms of cervical cancer } \\
\hline Excessive vaginal bleeding & 25 & 14.7 \\
\hline Malodorous vaginal discharge & 72 & 42.4 \\
\hline Abdominal pain & 58 & 34.1 \\
\hline Post coital bleeding & 39 & 22.9 \\
\hline Weight loss & 19 & 11.2 \\
\hline Cervical cancer be detected early & 137 & 80.6 \\
\hline Pap smear & 119 & 86.9 \\
\hline HPV DNA testing & 2 & 1.4 \\
\hline VIA* & 0 & 0 \\
\hline If detected early is it curable & 98 & 71.6 \\
\hline Pap smear is a cervical smear $(n=119)$ & 112 & 94.1 \\
\hline $\begin{array}{l}\text { Proper age for } 1^{\text {st }} \text { pap smear screening } \\
\text { smear is } 21 \text { years }\end{array}$ & 48 & 40.3 \\
\hline Pap smear done & 5 & 2.9 \\
\hline
\end{tabular}

\section{DISCUSSION}

As a result of infrastructural, financial and personnel constraints and absence of a nationally organized screening program, cervical cancer is a major killer among cancers in India, especially in rural settings. More than three-fourths of cervical cancer patients are diagnosed at advanced stages leading to poor long-term survival and cure. In India, the doctor to patient ratio is low, hence staff nurses has to be trained properly to make aware and screen all the women coming to hospital for any of their problems including cervical cancer.

In the present study, $85 \%$ nurses were aware about term cervical cancer. This was better than observed in the study done in Nalgonda district, Andhra Pradesh by Poonam R. Naik et al. ${ }^{11}$ where only $30 \%$ participants were aware of the term. Almost half of nurses in our survey were able to recognize cervical cancer as a major public health problem. Forty five percent knew that cancer cervix is the most common gynaecological cancer in India and thirty percent knew that it is the leading cause of mortality amongst the gynaecological cancer. This was in accordance to study done by Shashank Shekhar et al. ${ }^{12}$ where $76.9 \%$ participants reported so. Also, these observations were better than the findings in other study from Pakistan done by Ali SF et al. ${ }^{13}$ where only quarter of the nurses were aware of this.

Risk factors for cervical cancer include early onset of sexual activity, multiple sexual partners, history of sexually transmitted diseases, smoking, high parity, immunosuppression, low socioeconomic status, prolonged use of oral contraceptives. In our study, $48.2 \%$ nurses mentioned multiple sexual partners as one of the risk factors, which was better than study by V Shaw et al. ${ }^{14}$ where only $11.2 \%$ mentioned multiple partners and other promiscuous behaviour as the most common risk factor. Majority of the nurses didn't knew about the other risk factors like young age at first intercourse (12.9\%), cigarette smoking $(15.9 \%)$, high parity $(9.4 \%)$ and low socioeconomic status $(12.9 \%)$ are risk factors for cancer cervix. This is in accordance with the study done by Goyal A et al. ${ }^{15}$ in Surat, India where $61.5 \%$ and $44 \%$ knew multiple sexual partners and intercourse at early age as risk factors but only $12 \%$ and $3.5 \%$ knew about contraception and smoking as risk factors. These were also in accordance to the study done by Ali SF et al. ${ }^{13}$ where $45 \%$ of the participant knew promiscuity as risk factor for cervical cancer but other risk factors were lesser known. Only 38 participants were aware that HPV infection can leads to cervical cancer and 34 (89.5\%) of these participant correctly knew that HPV is transmitted by sexual intercourse. In the study from Etawah India done by Ekta Singh et al. ${ }^{16}$ only $54 \%$ of the respondents had heard of the HPV. These results again show insufficient knowledge of HPV infection being the cause of cervical cancer in health professionals, even though $98 \%$ of cervical cancer are due to HPV infection, as reported in various studies in India. ${ }^{17,18}$

In our study majority of nurses were not aware of any of the presenting symptoms. Only $25(14.7 \%)$ of the nurses knew cancer cervix is associated with excessive vaginal bleeding, $72(42.4 \%)$ knew about malodorous discharge, $39(22.9 \%)$ knew about post coital bleeding as presenting 
symptom. Similar observation were noted in a study in our neighbouring state Andhra Pradesh by Poonam R. Naik et al. 38 where only $24.2 \%$ of the participants were aware of the symptoms of cervical cancer. This emphasizes on the need to increase the awareness about cervical cancer in nurses who are involved in the primary care of general patient population and form an important source of guidance for them. In the present study, $68.8 \%$ knew that there are precancerous lesions of cervix. Majority $80.65 \%$ of them knew that there test available for early detection of cancer cervix. Around $86.86 \%$ of the nurses correctly knew Pap smear to be one. If detected early $71.5 \%$ of them reported it to be curable. Similarly in the study by Goyal A et al. ${ }^{15}$ approximately $70 \%$ participants believed that cancer cervix is curable if detected early. Pap smear was recognized as major screening technique by $74 \%$ participants. In our study only $5(4 \%)$ of the participants had ever done a pap smear for themselves. Among these 5 participant, 4 (80\%) had only once Pap smear. Only one participant had Pap smear done three times for herself. Similar observations were made in the study done by Chamaraja Thippeveeranna et al. ${ }^{19}$ where only $11.6 \%$ had Pap smear at least once previously.

This is the only study of its kind in South India and has assessed the various aspects of knowledge, awareness and practices regarding cervical cancer and prevention among nursing staff, the findings will be suggestive of need of training for them. Further, their role after involvement in the cancer prevention should be assessed to exactly define and improving the programme. This study concluded that although nurses identify certain aspects of cervical cancer, their knowledge is not adequate. They are aware of burden of cervical cancer but their knowledge regarding risk factors, cause and symptoms is limited. The knowledge of Pap smear as screening procedure is adequate but practice is very low. Before involving them as key persons in cervical cancer programme, there is a need for proper training of nursing and other paramedical staff.

\section{ACKNOWLEDGEMENTS}

The authors would like to thanks all the study participants for their support during the interview and also would like to acknowledge Indian Council of Medical Research (ICMR) for allowing this study under Short Term Studentship.

Funding: The study was funded by Short Term Studentship (STS) grant from ICMR

Conflict of interest: None declared

Ethical approval: The study was approved by the institutional ethics committee, PIMS

\section{REFERENCES}

1. Ferlay J, Shin HR, Bray F, Forman D, Mathers C, Parkin DM. Estimates of worldwide burden of cancer in 2008. Int J Cancer. 2010;127:2893-917.

2. Swaminathan R, Selvakumaran R, Esmy PO, Sampath P, Ferlay J, Jissa V, et al. Cancer pattern and survival in a rural district in South India. Cancer Epidemiol. 2009;33:325-31.

3. Laikangbam $P$, Sengupta $S$, Bhattacharya $P$, Duttagupta C, Dhabali Singh T, Verma Y, et al. A comparative profile of the prevalence and age distribution of human papillomavirus type 16/18 infections among three states of India with focus on northeast India. Int J Gynecol Cancer. 2007;17:10717.

4. WHO. WHO guidance note: comprehensive cervical cancer prevention and control: a healthier future for girls and women. Available at: http://apps.who.int/iris/bitstream/10665/78128/3/978 9241505147_eng.pdf?ua=1. Accessed 30 July 2014.

5. Adeleke NA, Komolafe JA. Knowledge, attitude and practice of cervical cancer screening among women of reproductive age group in Osogbo, south western Nigeria. Sex Health Matters. 2007;8:70-3.

6. Basu P, Chowdhury D. Cervical cancer screening \& HPV vaccination: a comprehensive approach to cervical cancer control. Indian $\mathrm{J}$ Med Res. 2009; 130:241-6.

7. Leung SS, Leung I. Cervical cancer screening: knowledge, health perception and attendance rate among Hong Kong Chinese women. Int J Womens Health. 2010;2:221-8.

8. Gu C, Chan CW, Twinn S. How sexual history and knowledge of cervical cancer and screening influence Chinese women's screening behavior in mainland China. Cancer Nurs. 2010;33:445-53.

9. Ackerson K. Personal influences that affect motivation in Pap smear testing among African American women. J Obstet Gynecol Neonatal Nurs. 2010;39:136-46.

10. Turkistanli EC, Sogukpinar N, Saydam BK, Aydemir G. Cervical cancer prevention and early detection: the role of nurses and midwives. Asian Pac J Cancer Prev. 2003;4:15-21.

11. Poonam R. Naik, K. Nagaraj, Abhay Subhashrao Nirgude. Awareness of cervical cancer and effectiveness of educational intervention programme among nursing students in a rural area of Andhra Pradesh. Healthline. 2012;3(2):41-5.

12. Shashank Shekhar, Chanderdeep Sharma, Sita Thakur, Nidhi Raina. Cervical cancer screening: knowledge, attitude and practices among nursing staff in a tertiary level teaching institution of rural India. Asian Pac J Cancer Prev. 2013;14(6):3641-5.

13. Ali SF, Ayub S, Manzoor NF, Azim S, Afif M, Akhtar N, et al. Knowledge and awareness about cervical cancer and its prevention amongst interns and nursing staff in tertiary care hospitals in Karachi, Pakistan. PLoS One. 2010;5(6):e11059. 
14. Shah V, Vyas S, Singh A, Shrivastava M. Awareness and knowledge of cervical cancer and its prevention among the nursing staff of a tertiary health institute in Ahmedabad, Gujarat, India. Ecancermedicalscience. 2012;6:270.

15. Goyal A, Vaishnav G, Shrivastava A, Verma R, Modi A. Knowledge, attitude \& practices about cervical cancer and screening among nursing staff in a teaching hospital. Int $\mathbf{J}$ Med Sci Public Health. 2013;2(2):249-53.

16. Ekta Singh, Shikha Seth, Vidya Rani, Dhiraj Kumar Srivastava. Awareness of cervical cancer screening among nursing staff in a tertiary institution of rural India. J Gynecol Oncol. 2012;23(3):141-6.

17. Sowjanya AP, Jain M, Poli UR, Padma S, Das M, Shah KV, et al. Prevalence and distribution of highrisk human papilloma virus (HPV) types in invasive squamous cell carcinoma of the cervix and in normal women in Andhra Pradesh, India. BMC Infect Dis. 2005;5:116.

18. Clifford GM, Gallus S, Herrero R, Muñoz N, Snijders PJ, Vaccarella S, et al. Worldwide distribution of human papillomavirus types in cytologically normal women in the international agency for research on cancer HPV prevalence surveys: a pooled analysis. Lancet. 2005;366:991-8.

19. Chamaraja Thippeveeranna, Surekha Sadhana Mohan, Laiphrakpam Ranjit Singh, Naorem Nabakishore Singh. Knowledge, attitude and practice of the Pap smear as a screening procedure among nurses in a tertiary hospital in North Eastern India. Asian Pacific J Cancer Prev. 2013;14(2):849-52.

DOI: $10.5455 / 2320-1770 . i j r \operatorname{cog} 20141235$

Cite this article as: Dhodapkar SB, Chauhan RC, Thampy S. Knowledge and awareness of cervical cancer and its prevention among nursing staff of a tertiary care teaching institute in South India. Int J Reprod Contracept Obstet Gynecol 2014;3:1056-60. 